\title{
Effects of calcium hydroxide reagent on the bond strength of resin cements to root dentin and the retention force of FRC posts
}

\author{
Tomoko SOMEYA ${ }^{1,2}$, Hideaki KINOSHITA ${ }^{1}$, Rino HARADA ${ }^{1,2}$, Eiji KAWADA ${ }^{1}$ and Shinji TAKEMOTO ${ }^{1,2}$ \\ ${ }^{1}$ Department of Dental Materials Science, Tokyo Dental College, 2-9-8 Misaki-cho, Chiyoda-ku, Tokyo 101-0061, Japan \\ ${ }^{2}$ Oral Health Science Center, Tokyo Dental College, 2-9-8 Misaki-cho, Chiyoda-ku, Tokyo 101-0061, Japan \\ Corresponding author, Shinji TAKEMOTO; E-mail: takemoto@tdc.ac.jp
}

\begin{abstract}
The aim of this study was to determine the effects of calcium hydroxide $\left(\mathrm{Ca}(\mathrm{OH})_{2}\right)$ treatment on bond strength of resin cements to root dentin and retention force of fiber-reinforced composite (FRC) posts. Bovine root dentin was endodontically prepared and treated with $\mathrm{Ca}(\mathrm{OH})_{2}$ for 7 days. Root dentin for bond strength test was adhered to resin-composite with resin cements. For pull-out test, posts consisting of FRC posts and resin-composites were fabricated and cemented to root. Shear bond and pull-out tests were performed using a universal testing machine. No significant differences in bond strength and post retention force were found between $\mathrm{Ca}(\mathrm{OH})_{2}$ treated and untreated groups. Significant differences were found among the cements. A positive correlation was indicated between bond strength of cements and retention force of FRC posts. In conclusion, $\mathrm{Ca}(\mathrm{OH})_{2}$ treatment on root dentin did not affect bond strength of resin cements and retention force of FRC posts.
\end{abstract}

Keywords: FRC post, Adhesive resin cement, Calcium hydroxide, Bond strength, Post retention

\section{INTRODUCTION}

Posts and cores are used as filling materials on endodontically treated tooth to ensure adequate retention of the final crown restoration. Metals have been conventionally used as post material due to their exceptional strength, however the probability of tooth fracture increases from stress generated between the post and dentin from the large difference in elastic modulus ${ }^{1)}$.

Fiber reinforced composite resin (FRC) posts possess exceptional aesthetic properties and an elastic modulus which closely matches dentin which reduces the risk of severe tooth fractures compared to metal posts ${ }^{2,3)}$. However inadequate adhesion between root dentin and posts have caused clinical complications such as post debonding-6); therefore it is important to have sufficient adhesion between root dentin and post material for adequate post retention. Studies on the adhesive or retention force between dentin, post, and core materials have been reported ${ }^{7,8}$; however very few have investigated the relationship between bond strength of root dentin to resin composite and retention force of FRC posts.

Techniques for core build-up on endodontically treated teeth with FRC posts include the following: the direct method, where a bonding agent is used to directly build-up the core with a fiber post and resin composite, the indirect method, where the FRC post is fabricated outside the oral cavity and bonded later using adhesive resin cement, and the indirect-direct method, where the FRC post is fabricated in the patients mouth and bonded later. Higher retention force of posts and fracture resistance of teeth have been reported when adhesive resin cements were used, compared to non-resin cements, to bond posts to root dentin ${ }^{9}$. Post debonding often occurs interfacially between root dentin and adhesive resin cement however not as common between FRC post and resin composite ${ }^{10,11}$. Therefore it is important to determine any substances which may affect the bond strength and retention force at the interface between dentin and resin cements when FRC post are bonded.

Root canal treatment is a complicated procedure where remains of root canal reagents can affect the adhesive system during post and core build-up. For example, sodium hypochlorite and hydrogen peroxide, used for root canal irrigation, are known to decrease bond strength of adhesive resin cements ${ }^{12,13}$. Calcium hydroxide reagents, which have been shown to be challenging to completely remove from root canals, are also commonly used on root canals as antibacterial medication $^{14-17)}$. Calcium hydroxide remains after endodontic treatment could possibly affect the bond strength of dentin to resin cements; however this subject has not yet been studied much.

The purpose of this study was to determine the effects of calcium hydroxide reagent on the bond strength of resin cement to root dentin and the retention force of FRC posts. In addition, the relationship between bond strength of resin cement to root dentin and retention force of FRC posts was also discussed. The null hypothesis was that the application of calcium hydroxide reagent on root dentin decreases both the bond strength of resin cements and retention force of FRC posts.

\section{MATERIALS AND METHODS}

\section{Preparation of bovine tooth root canals}

Two types of specimens were fabricated for the shear bond strength test and the pull-out test. Seventy bovine anterior teeth were prepared for each test. Previously frozen extracted bovine teeth were thawed and the crown 
was cut above the cement enamel junction using a fine cutter (HS-100, Heiwa Technica, Kanagawa, Japan). Soft tissues surrounding the root and the tooth pulp were removed using hand scalers and endodontic files.

\section{Preparation of specimens for shear bond strength test} Specimen design for shear bond test is shown in Fig. 1(a). Tooth roots were cut in half vertically and embedded perpendicular to the longitudinal axis with epoxy resin (Scandiplex, Fritsch Japan, Yokohama, Japan) in epoxy rings. Waterproof abrasive papers 120 grit were used on the root surface until dentin exposure then sequentially polished to 600 grit. Root canal treatment was performed on the dentin surface by applying $1 \mathrm{~mL}$ of $3 \%$ sodium hypochlorite $\left(\mathrm{NaOCl}\right.$; ChlorCid ${ }^{\circledR}$ J, Ultradent Japan, Tokyo, Japan) for $20 \mathrm{~s}$, drying with paper points, then applying $2 \mathrm{~mL}$ of $18 \%$ ethylenediaminetetraacetic acid (EDTA; Ultradent ${ }^{\circledR}$ EDTA18\%, Ultradent Japan) for $20 \mathrm{~s}$, and irrigating with distilled water. After air drying, calcium hydroxide reagent $\left(\right.$ Calvital $^{\circledR}$, Neo dental chemical products, Tokyo, Japan), mixed at a powder to liquid ratio of $2: 1(\mathrm{P} / \mathrm{L})$, was applied on the dentin surface of half of the specimens. All specimens were stored in a sealed container with a small amount of water and incubated at $37^{\circ} \mathrm{C}$ and $95 \%$ humidity for 7 days. After 7 days, calcium hydroxide treated specimens were ultrasonically cleaned for $1 \mathrm{~min}$ with distilled water to remove the reagent.

Cylindrical specimens were made with resin composites and used as adhesive substrates. Acrylic rings with an inner diameter of $6 \mathrm{~mm}$ and thickness of $2 \mathrm{~mm}$ were filled with resin composite (Clearfil $^{\circledR}$ DCcore Automix $^{\circledR}$ ONE, Kuraray Noritake Dental, Tokyo, Japan). The surface was pressed with glass plates and light cured for $30 \mathrm{~s}$. The cylindrical substrate was bonded to dentin surface after root canal treatment using various resin cements shown in Table 1 . Two types of adhesives requiring pretreatment, Panavia ${ }^{\circledR}$ F2.0 (PAF, Kuraray Noritake Dental) and RelyX ${ }^{\mathrm{TM}}$ Ultimate Adhesive Resin Cement (ULR, 3M ESPE, St. Paul, MN, USA) and 3 types of self-adhesive cements RelyX ${ }^{\mathrm{TM}}$ Unicem2 AutoMix (UNA, 3M ESPE), Clearfil ${ }^{\circledR}$ SA Luting (CSA, Kuraray Noritake Dental), and G-CEM (GCM, GC, Tokyo, Japan) were used. Three millimeter holes were punched on double sided tape (Teraoka Seisakusho, Tokyo, Japan) with thickness of $0.03 \mathrm{~mm}$. Tapes were placed on dentin surface to standardize the adhesive area. Dentin of PAF specimen was pretreated with self-etching primer (EDprimer II, Kuraray Noritake Dental). Primer was made by mixing liquid $\mathrm{A}$ and $\mathrm{B}$, and applied on dentin surfaces and air dried after 20 s. Dentin and substrate of ULR specimens were pretreated with bonding agent (ScotchBond ${ }^{\mathrm{TM}}$ Universal Adhesive, 3M ESPE) for $20 \mathrm{~s}$ then air dried. Adhesive resin cement was applied on the substrate surface and bonded to the dentin surface. After removal of excess cement, the area was light cured for $10 \mathrm{~s}$ from 4 directions. Specimens were stored in a closed container with a small amount of distilled water and incubated at $37^{\circ} \mathrm{C}$ and $95 \%$ humidity for 7 days. Seven

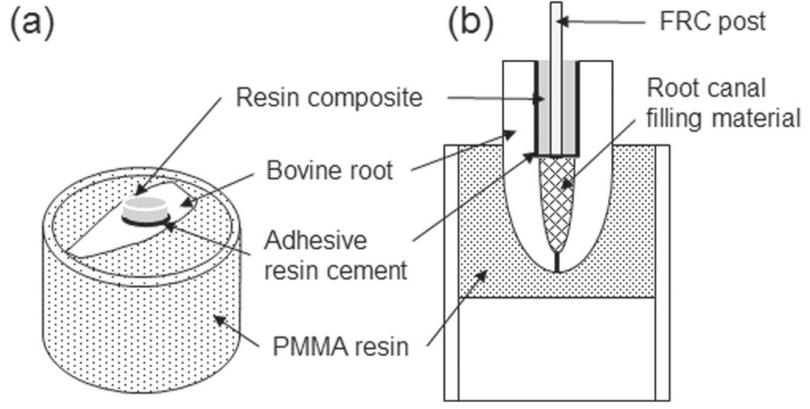

Fig. 1 Schematic of prepared bovine root for shear bond test (a) and bovine root for pull-out test (b).

specimens were prepared for each type of cement for calcium hydroxide treated and non-treated groups.

\section{Shear bond strength test}

After 7 days, specimens were taken out of storage and shear bond strength test was performed using a universal testing machine (EZ graph, Shimadzu, Kyoto, Japan) at a crosshead speed of $0.5 \mathrm{~mm} / \mathrm{min}$. Stress was applied on the adhesive substrate from the root apex in the coronal direction. Shear bond strength was calculated from the maximum fracture load. After testing, the fractured surfaces were observed under the stereomicroscope digital camera system (MZ 75, LEICA, Tokyo, Japan) to $\times 2.5$ magnification.

\section{Preparation of specimens for pull-out test}

Specimens design for pull-out test is shown in Fig. 1(b). Tooth with root canals less than $3 \mathrm{~mm}$ in diameter were selected. Specimens were fixed in acrylic rings with chemically activated resin (Tray Resin, Shofu, Kyoto, Japan) with the root canal perpendicular to the ring floor. Root canal treatment was performed on the dentin surface by applying $1 \mathrm{~mL}$ of $\mathrm{NaOCl}$ (ChlorCid ${ }^{\circledR} \mathrm{J}$, Ultradent Japan) for $20 \mathrm{~s}$, drying with paper points, then applying $2 \mathrm{~mL}$ of EDTA (Ultradent ${ }^{\circledR}$ EDTA18\%, Ultradent Japan) for $20 \mathrm{~s}$, and irrigating with distilled water. After air drying, root canal was obturated with gutta percha (Gutta-percha obturator, Morita, Tokyo, Japan). Post space $4.0 \mathrm{~mm}$ deep were prepared on tooth using a $3.0 \mathrm{~mm}$ drill, then rinsed with EDTA and distilled water.

Post was fabricated from FRC post $1.6 \mathrm{~mm}$ diameter (Fiber post, GC) and resin composite (Clearfil ${ }^{\circledR}$ DC core automix $^{\circledR}$ ONE, Kuraray Noritake Dental). The surface of FRC post was cleaned with ethanol then treated with silane coupling agent (Clearfil ${ }^{\circledR}$ CERAMIC PRIMER PLUS, Kuraray Noritake Dental). The post space was first filled with resin composite, then FRC post was placed into the post space until contact with canal floor at the root center and light cured for $10 \mathrm{~s}$. The post was then removed and light cured again from 4 angles for $10 \mathrm{~s}$ each and stored in a sealed container until use. For half of the specimens, dentin surfaces were treated with 
Table 1 Adhesives used in this study

\begin{tabular}{|c|c|c|c|}
\hline Adhesive resin cement & Main component & Pretreatment agent & Code \\
\hline $\begin{array}{l}\text { Panavia }{ }^{\circledR} \text { F2.0 } \\
\text { (Kuraray Noritake } \\
\text { Dental, Tokyo, Japan) } \\
\text { Lot No: 6L0069 (A paste) } \\
\text { Lot No: 6L0033 (B paste) }\end{array}$ & $\begin{array}{l}\text { A paste } \\
\text { methacrylate monomer, MDP, filler, } \\
\text { photo initiator, chemical initiator } \\
\text { B paste } \\
\text { methacrylate monomer, sodium fluoride, } \\
\text { photo initiator, chemical initiator }\end{array}$ & $\begin{array}{l}\text { ED primer II } \\
\text { A Liquid: HEMA, MDP, water, } \\
\text { chemical initiator (Lot No: 6C0014) } \\
\text { B Liquid: methacrylate monomer, } \\
\text { water, chemical initiator } \\
\text { (Lot No: 6G0014) }\end{array}$ & $\mathrm{PAF}$ \\
\hline $\begin{array}{l}\text { RelyX }{ }^{\mathrm{TM}} \text { Ultimate } \\
\text { Adhesive Resin Cement } \\
\text { (3M ESPE, MN, } \\
\text { St. Paul, USA) } \\
\text { Lot No: } 593236\end{array}$ & $\begin{array}{l}\text { Base paste } \\
\text { glass powder, methacrylate, silica, initiator } \\
\text { Catalyst paste } \\
\text { glass powder, methacrylate, silica, initiator }\end{array}$ & $\begin{array}{l}\text { Scotch BondTM Universal Adhesive } \\
\text { (Lot No: 587884) } \\
\text { phosphoric ester acid monomer, } \\
\text { methacrylate, initiator, ethanol }\end{array}$ & ULR \\
\hline $\begin{array}{l}\text { RelyX' }{ }^{\mathrm{TM}} \text { Unicem2 } \\
\text { AutoMix } \\
\text { (3M ESPE) } \\
\text { Lot No: } 612923\end{array}$ & $\begin{array}{l}\text { Base paste } \\
\text { glass powder, phosphoric ester monomer, } \\
\text { TEGDMA, silica, initiator } \\
\text { Catalyst paste } \\
\text { glass powder, methacrylate, silica, initiator }\end{array}$ & none & UNA \\
\hline $\begin{array}{l}\text { Clearfil }^{\circledR} \text { SA Luting } \\
\text { (Kuraray Noritake } \\
\text { Dental) } \\
\text { Lot No: 3J0063 }\end{array}$ & $\begin{array}{l}\text { Paste A } \\
\text { Bis-GMA, TEGDMA, MDP, methacrylate } \\
\text { monomer, filler, photo initiator, chemical } \\
\text { initiator } \\
\text { Paste B } \\
\text { Bis-GMA, methacrylate monomer, sodium } \\
\text { fluoride, filler, accelerator }\end{array}$ & none & CSA \\
\hline $\begin{array}{l}\text { G-CEM } \\
\text { (GC, Tokyo, Japan) } \\
\text { Lot No: } 1507161\end{array}$ & $\begin{array}{l}\text { Powder } \\
\text { fluoro aluminosilicate glass, polymerization } \\
\text { initiator, colorant } \\
\text { Liquid } \\
\text { methacrylic ester, 4-AET, phosphoric acid } \\
\text { ester monomer, water, silica, initiator }\end{array}$ & none & $\mathrm{GCM}$ \\
\hline
\end{tabular}

calcium hydroxide reagent, mixed at a powder to liquid ratio of $2: 1(\mathrm{P} / \mathrm{L})$. All specimens were stored at $37^{\circ} \mathrm{C}$ and 95\% humidity. After 7 days, calcium hydroxide treated specimens were ultrasonically cleaned for $1 \mathrm{~min}$ with distilled water to remove the reagent. Fabricated post was luted to respective dentin specimen using adhesive resin cements shown in Table 1. Excessive cement was removed and light cured from 4 directions for $20 \mathrm{~s}$ each. After placing post, specimens were stored in a closed container with a small amount of water and incubated at $37^{\circ} \mathrm{C}$ and $95 \%$ humidity for 7 days. Seven specimens were prepared for each type of cement for calcium hydroxide treated and non-treated groups.

\section{Pull-out test}

After 7 days, specimens were taken out of storage and pull-out test was performed using a universal testing machine (EZ graph, Shimadzu) at a crosshead speed of $0.5 \mathrm{~mm} / \mathrm{min}$. Retention force was considered the maximum pull-out force. After testing, fractured surfaces were investigated under the stereo microscope digital camera system $(\times 1.25$ magnification).

\section{SEM observations}

The surface of resin composite specimens after shear bond strength test, and dentin specimens after polishing, post space preparation, EDTA treatment, calcium hydroxide treatment and ultrasonic cleaning, and shear bond strength tests was observed under the field emission scanning electron microscopy (FE-SEM: SU6600, HITACHI, Tokyo, Japan).

\section{Statistical analysis}

All statistical testing was performed using software (Ekuseru-Toukei 2015, Social Survey Research Information, Tokyo, Japan). The bond strength and the retention force of posts with and without calcium hydroxide treatment and with various resin adhesives were statistically analyzed using two-way analysis of variance (ANOVA) and Tukey's multiple comparison test. The Spearman's rank correlation coefficient was used to investigate the relationship between shear bond 
strength and retention force of posts. Significance level was set at $5 \%(\alpha=0.05)$.

\section{RESULTS}

SEM observation of treated surface

Figure 2 shows the root dentin surface after polishing, post preparation, EDTA treatment, and ultrasonic cleaning. The surface of specimens after polishing (Fig. 2(a)) and post space preparation (Fig. 2(b)) had a smear layer covering the dentinal tubules. After EDTA treatment (Fig. 2(c)) the smear layer was removed and dentinal tubules were exposed. After 7 days of calcium hydroxide treatment (Fig. 2(d)), images showed unidentifiable deposits on the dentinal surface and tubules even after ultrasonic cleaning.

\section{Shear bond strength and fracture mode}

Figure 3 demonstrates shear bond strength of various adhesives when bonded to root dentin. Shear bond strength of adhesive resin cements ranged from 4 to

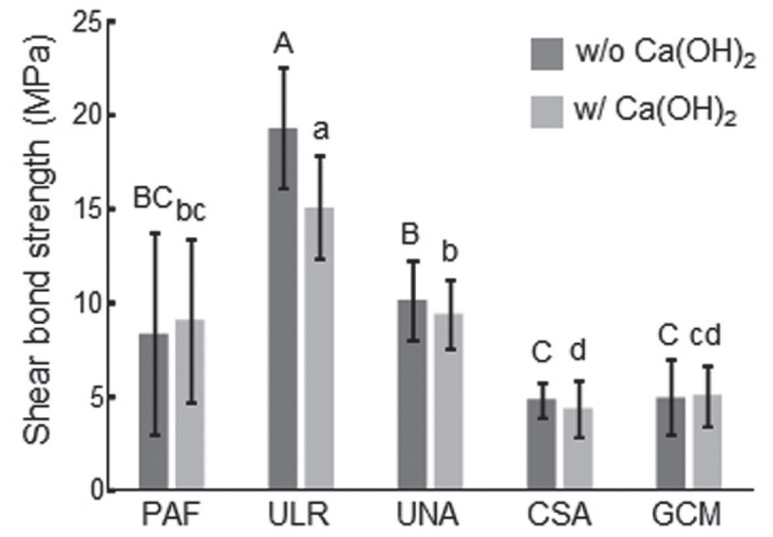

Fig. 3 Shear bond strengths of resin composites bonded to root dentin.

The same letter in the same case indicates no significant differences. Large case letters indicates no calcium hydroxide treatment and small case letters indicates calcium hydroxide treatment.
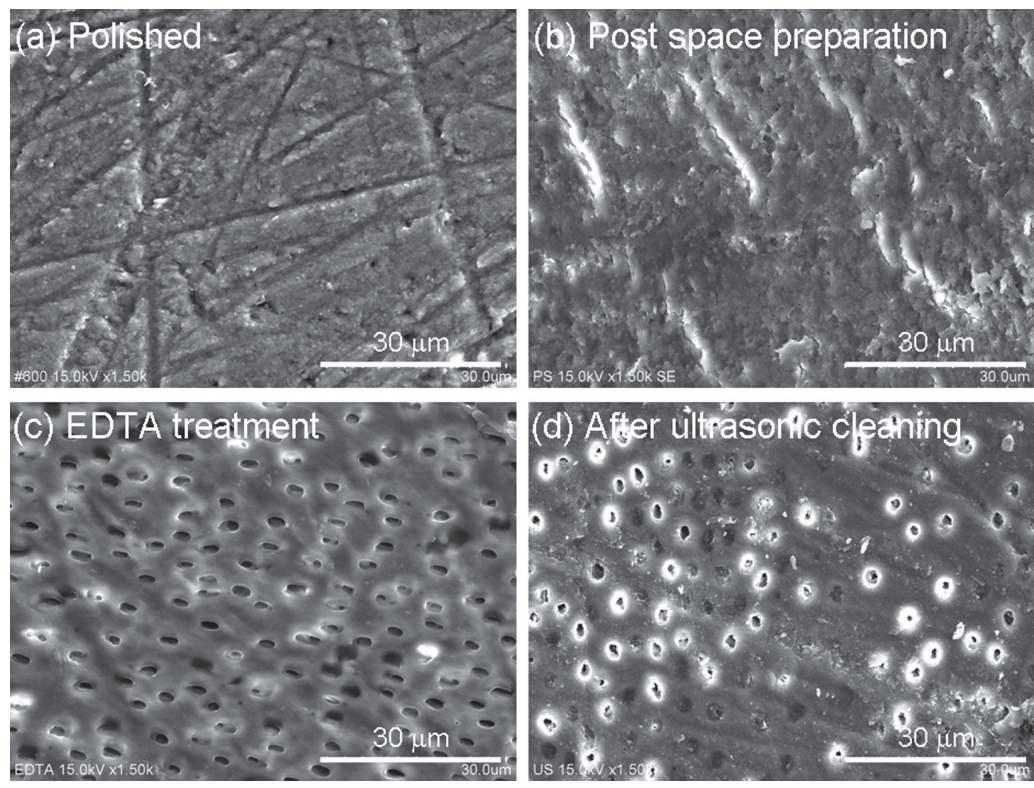

Fig. 2 SEM images of root dentin after procedures.

(a) Polished, (b) Post space preparation, (c) EDTA treatment, (d) ultrasonically cleaned after 1 week of calcium hydroxide treatment

Table 2 Results of two-way ANOVA for shear bond strength

\begin{tabular}{lccccc}
\hline & Sum of squares & df & Mean square & $F$ & $p$ \\
\hline A: Cement & $1,442.705$ & 4 & 360.676 & 43.365 & 0.000 \\
B: Calcium hydroxide reagent & 14.846 & 1 & 14.846 & 1.785 & 0.187 \\
Interaction A*B & 52.896 & 4 & 13.224 & 1.590 & -189 \\
Error & 499.036 & 60 & 8.317 & - \\
Total & $2,009.483$ & 69 & - & - \\
\hline
\end{tabular}


$15 \mathrm{MPa}$ when treated with calcium hydroxide reagent. Table 2 shows results of two-way ANOVA for shear bond strength. No significant differences were found between

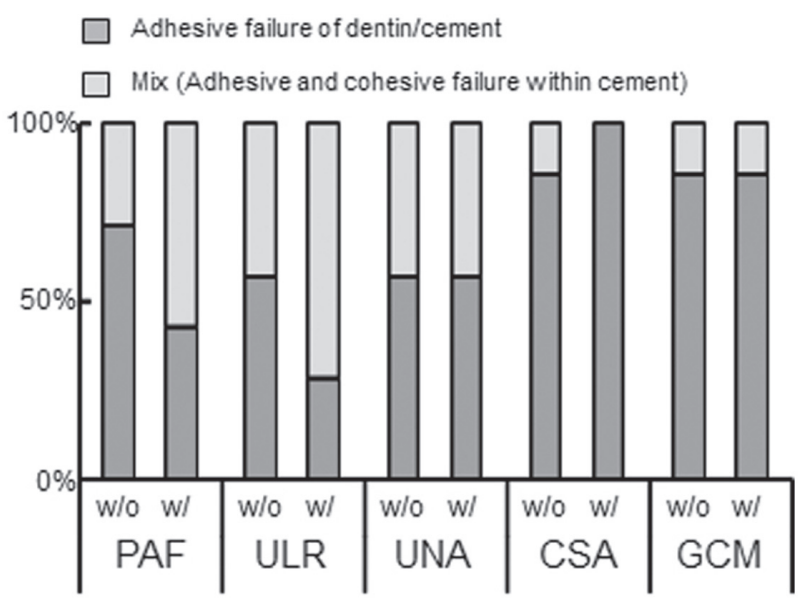

Fig. 4 Failure modes of specimens that underwent shear bond strength test. the calcium hydroxide treated and non-treated groups for all types of cements $(p>0.05)$; however significant differences were found between the various adhesive resin cements $(p<0.05)$. The interaction between calcium hydroxide treatment and adhesive cements did not significantly affect shear bond strength $(p>0.05)$. ULR possessed the greatest shear bond strength with $15 \pm 3 \mathrm{MPa}$; CSA and GCM possessed lower shear bond strength at approximately $5 \mathrm{MPa}$.

Figure 4 shows the fracture mode of specimens after shear bond strength test. Most of CSA and GCM specimens showed adhesive failure at the interface between root dentin and resin composite regardless of calcium hydroxide treatment. PAF, ULR, and UNA demonstrated cohesive failure in $42-57 \%$ of specimens. Figures 5(a)-(j) displays SEM images of dentinal surface with and without calcium hydroxide treatment. Specimens without treatment displayed remains of adhesive resin cement in the dentinal tubules. Specimens with treatment revealed unidentifiable deposits in addition to adhesive resin cement remains in the dentinal tubules.

Figure 6 displays the resin composite surface after
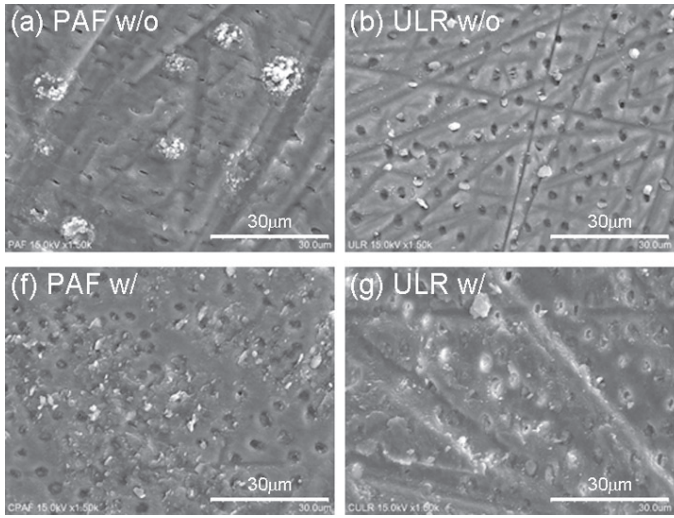
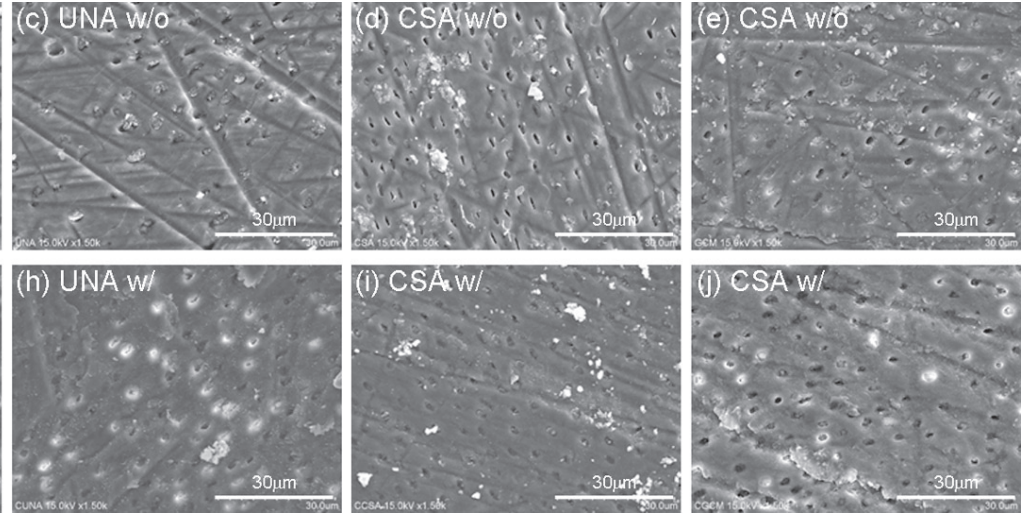

Fig. 5 SEM observation of dentin surface after shear bond strength test.

(a) and (f) PAF, (b) and (g) ULR, (c) and (h) UNA, (d) and (i) CSA, (e) and (j) GCM

(a)-(e): dentinal surface without calcium hydroxide treatment

(f)-(j): dentinal surface with calcium hydroxide treatment
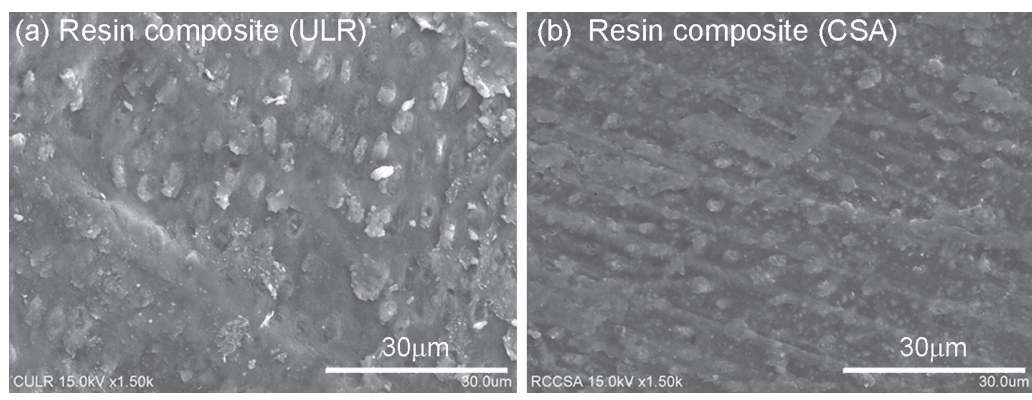

Fig. 6 Typical resin composite surfaces after shear bond strength test. Both composites were bonded to root dentin after calcium hydroxide treatment. (a) ULR, (b) CSA 


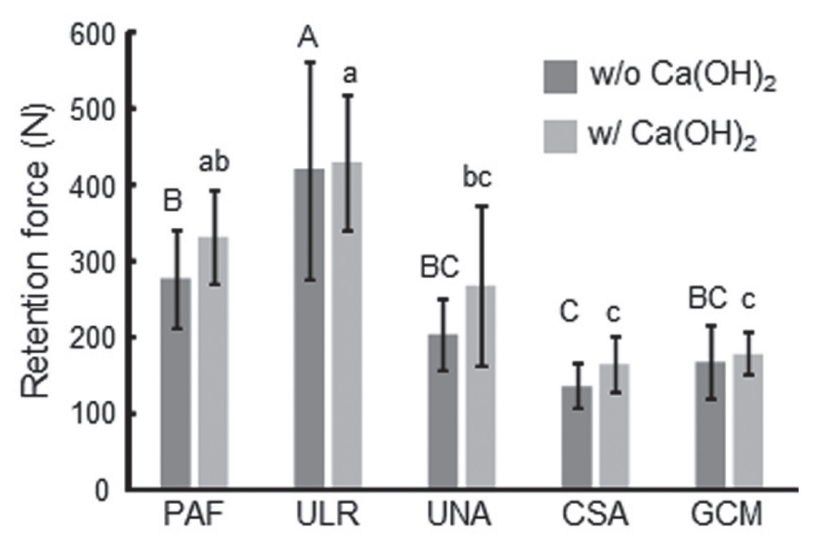

Fig. 7 Retention force of posts bonded to root dentin with adhesive resin cements.

The same letter in the same case indicates no significant difference. Large case letters indicates no calcium hydroxide treatment and small case letters indicates calcium hydroxide treatment.

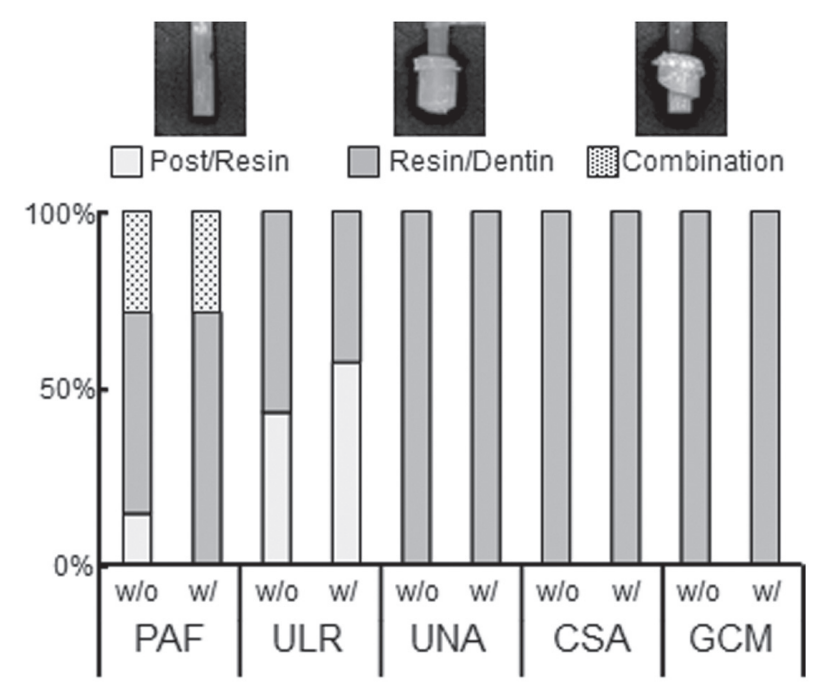

Fig. 8 Fracture mode after pull-out test.

Table 3 Results of two-way ANOVA for retention force of FRC posts

\begin{tabular}{lrrrrc}
\hline & Sum of squares & df & Mean square & \multicolumn{1}{c}{$F$} & $p$ \\
\hline A: Cement & $685,871.057$ & 4 & $171,467.764$ & 31.142 & 0.000 \\
B: Calcium hydroxide reagent & $20,094.229$ & 1 & $20,094.229$ & 3.649 & 0.061 \\
Interaction A*B & $8,799.343$ & 4 & $2,199.836$ & 0.400 & 0.808 \\
Error & $330,362.857$ & 60 & $5,506.048$ & - & - \\
Total & $1,045,127.486$ & 69 & - & - & - \\
\hline
\end{tabular}

shear bond strength test with root dentin that was treated with calcium hydroxide reagent. Resin tags of adhesives were observed on some of the specimens.

\section{Retention force of posts and fracture mode}

Figure 7 displays the retention force of posts bonded with adhesive resin cements. Table 3 shows result of two-way ANOVA for retention force of FRC posts. Results were similar to that of bond strength in that the retention force of posts with and without calcium hydroxide reagent showed no significant differences $(p>0.05)$. Significant differences were found among the adhesive resin cements $(p<0.05)$. The interaction between calcium hydroxide treatment and adhesive cements did not significantly affect retention force $(p>0.05)$. ULR demonstrated the largest retention force with $400 \pm 144 \mathrm{~N}$; CSA and GCM demonstrated lower at approximately $150 \mathrm{~N}$.

Figure 8 shows the fracture mode of specimens after pull-out test. UNA, CSA, GCM specimens all showed adhesive failure between root dentin and post. PAF and ULR specimens showed either adhesive failure between resin composite and FRC post or cohesive failure of resin composite.

\section{DISCUSSION}

This study investigated the effects of calcium hydroxide reagent on the bond strength and retention force of FRC post on root dentin. Calcium hydroxide reagents are used during root canal treatments before post preparation. The application of calcium hydroxide reagent on root canals may alter the microstructure of root dentin by reacting with salivary components to produce calcium carbonate and calcium phosphate. In this paper, structural changes due to calcification cannot be expected since the specimens were placed in solution without mineral elements after the application of calcium hydroxide. Root canal treatment itself is a complicated procedure and many steps are involved. However shear bond strength test and pull-out test were used as a simplify method in order to investigate the effects of calcium hydroxide remaining on root dentin which could often occur in a clinical setting ${ }^{18)}$.

\section{Calcium hydroxide reagent treatment}

Calcium hydroxide reagents are effective for root canal treatments due to their high $\mathrm{pH}$ which leads to antibacterial effects ${ }^{14}$. Lee et al. studied the bond 
strength of FRC post on root canal dentin via push-out method and reported that calcium hydroxide treatment decreases bond strength of adhesive resin cement ${ }^{18)}$. However other studies using shear bond strength test and micro tensile test indicated that calcium hydroxide treatment on root dentin does not affect bond strength to resin cement ${ }^{19,20)}$. These studies indicate that there is still no consensus on the effects of calcium hydroxide reagents on bond strength to resin cement. In our study, calcium hydroxide treatment on root dentin had no effect on the bond strength of resin cement to root dentin, and on the retention force of post made with FRC post and resin composite. Therefore the null hypothesis that calcium hydroxide decreases bond strength and retention force of post bonded to root dentin via adhesive resin cement can be rejected.

After root canal treatment, the remains of medicinal reagents can affect the adhesive system during post and core build-up. The general root canal procedure involves treatment with sodium hypochlorite and EDTA to remove the smear layer and expose the dentinal tubules (Fig. 2(c)). When calcium hydroxide was applied to dentin surface and ultrasonically cleaned, SEM images showed that dentinal tubules were partially exposed; however some calcium hydroxide still remained in the tubules (Fig. 2(d)). The fracture surface of dentin after shear bond strength test showed damaged resin tags as well as exposed dentinal tubules in both calcium hydroxide treated groups and non-treated groups (Fig. 5). In addition, the fracture surface of resin composite specimens had structures which appeared to be detached resin tags (Fig. 6). Studies up until now indicated that there is no effective way to completely remove calcium hydroxide from root canals ${ }^{15-17)}$. Since calcium hydroxide is alkaline, the condition may neutralize etching agents and acidic monomers in bonding agents, thereby decreasing the bond strength. However, our results indicated that calcium hydroxide had no effect on the bond strength and retention force of posts on root dentin. The reason for this is that ultrasonic cleaning after calcium hydroxide treatment most likely washed off a majority of the remaining reagent for it to affect the adhesive system.

Shear bond strength and post retention force

Evaluation methods for bond strength of dental materials in dentistry usually include the micro-tensile and shear bond strength test ${ }^{8,21-26)}$. Root dentin has lower potential for bonding with less exposure of dentinal tubules compared to coronal dentin ${ }^{27)}$; reagents used during root canal treatment can affect bond strength even more ${ }^{13,22)}$. In this study, we investigated the effects of calcium hydroxide on the bond strength of root dentin by bonding to resin composite, a core build-up material, with adhesive resin cement. Bond strength significantly varied among the types of adhesive resin cements used. A number of studies have been undertaken to compare the bond strength of various resin cements to dentin ${ }^{8,21,23-26,28)}$. Most of these studies reported that adhesive resin cements, that require pretreatment,

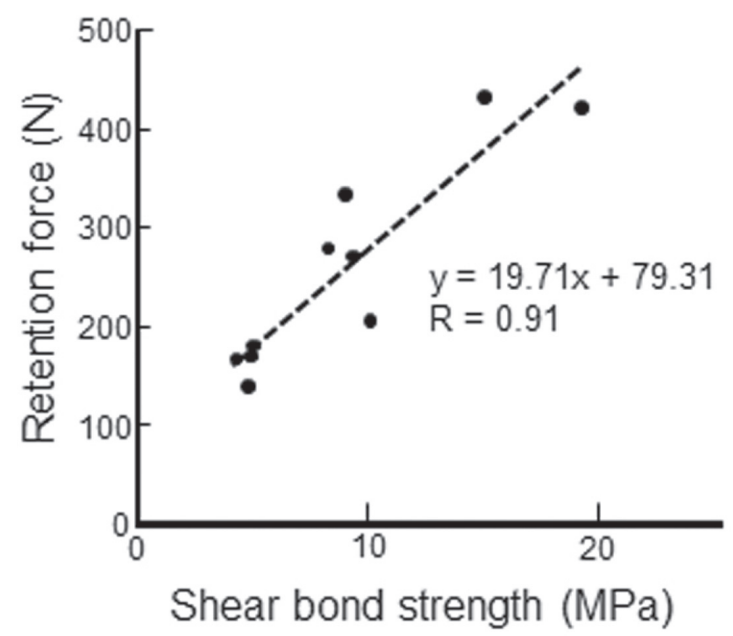

Fig. 9 Correlation of post retention force and shear bond strength.

have higher bond strength compared to self-adhesive resin cements ${ }^{23,24,26)}$. These results are consistent with our study where adhesive resin cements, ULR and PAF, which require pretreatment demonstrated greater bond strength.

Post retention is usually evaluated through pushout or pull-out tests. The push-out test is effective for evaluating bond strength of root dentin at different sections ${ }^{18}$. This study used the pull-out test to evaluate the adhesion resistance of post in root canals to consider post debonding which is a frequent clinical complication $^{28)}$. As previously discussed, posts bonded with PAF and ULR requiring pretreatment, displayed higher retention force compared to self-adhesive resin cements UNA, CSA and GCM (Fig. 7). The explanation for this observation can be the fact that self-adhesive cements take time to completely cure, indicated in the study by Soejima et al. where the mechanical strength of self-adhesive resin cements increased after 14 days ${ }^{7}$. In addition, self-adhesive cements possess low retention force of posts due to insufficient formation of resin tags ${ }^{7}$. In our study, bond strength and retention force of posts was most likely influenced by the time of before testing.

Figure 9 displays the correlation between retention force of post and shear bond strength. The correlation coefficient $(\mathrm{R})$ was 0.91 indicating a strong correlation $(p<0.05)$. The $\mathrm{y}$-intercept value was a positive value indicating that even without cement for adhesion, factors other than retention force had an influence on bond strength. This other factor is most likely friction which exists between the root dentin and cement ${ }^{28)}$. In this study, a cylindrical post space was prepared where FRC post and resin composite was used to make a fitted core which could be sufficiently cured before placement. In this situation where the post-and-core build-up resin composite is fully cured, the bond strength of resin cement would be considerably large resulting in 
high retention force. As study has shown that the post shape is related to its fracture resistance ${ }^{29)}$; therefore further investigation is required to understand the relationship between post shape and retention force on endodontically treated tooth.

\section{CONCLUSIONS}

In this study, the effects of calcium hydroxide treatment on shear bond strength and retention force of posts of adhesive resin cements to root dentin was investigated. Within the limitation of this study, the following was concluded:

1. Calcium hydroxide treatment on root dentin did not affect both the shear-bond strength of adhesive resin cements and the retention of posts.

2. There was a correlation between shear bond strength and retention force of posts of adhesive resin cements; specimens with high shear bond strength generally demonstrated high retention force of posts.

\section{REFERENCES}

1) Barjau-Escribano A, Sancho-Bru JL, Forner-Navarro L, Rodriguez-Cervantes PJ, Perez-Gonzalez A, Sanchez-Marin FT. Influence of prefabricated post material on restored teeth: fracture strength and stress distribution. Oper Dent 2006; 31: 47-54.

2) Martinez-Insua A, da Silva L, Rilo B, Santana U. Comparison of the fracture resistances of pulpless teeth restored with a cast post and core or carbon-fiber post with a composite core. J Prosthet Dent 1998; 80: 527-532.

3) Asmussen E, Peutzfeldt A, Heitmann T. Stiffness, elastic limit, and strength of newer types of endodontic posts. J Dent 1999; 27: 275-278.

4) Cagidiaco MC, Goracci C, Garcia-Godoy F, Ferrari M. Clinical studies of fiber posts: a literature review. Int J Prosthodont 2008; 21: 328-336.

5) Naumann M, Koelpin M, Beuer F, Meyer-Lueckel H. 10-year survival evaluation for glass-fiber-supported postendodontic restoration: a prospective observational clinical study. J Endod 2012; 38: 432-435.

6) Parisi C, Valandro LF, Ciocca L, Gatto MR, Baldissara P. Clinical outcomes and success rates of quartz fiber post restorations: A retrospective study. J Prosthet Dent 2015; 114: $367-372$.

7) Soejima H, Takemoto S, Hattori M, Yoshinari M, Kawada E, Oda Y. Effect of adhesive system on retention in posts comprising fiber post and core resin. Dent Mater J 2013; 32: 659-666.

8) Kensche A, Dahne F, Wagenschwanz C, Richter G, Viergutz G, Hannig C. Shear bond strength of different types of adhesive systems to dentin and enamel of deciduous teeth in vitro. Clin Oral Investig 2016; 20: 831-840.

9) Cheung W. A review of the management of endodontically treated teeth. Post, core and the final restoration. J Am Dent Assoc 2005; 136: 611-619.

10) Sahafi A, Peutzfeldt A, Asmussen E, Gotfredsen K. Retention and failure morphology of prefabricated posts. Int $\mathrm{J}$ Prosthodont 2004; 17: 307-312.

11) Nova V, Karygianni L, Altenburger MJ, Wolkewitz M, Kielbassa AM, Wrbas KT. Pull-out bond strength of a fibre- reinforced composite post system luted with self-adhesive resin cements. J Dent 2013; 41: 1020-1026.

12) Soeno K, Taira Y, Matsumura H, Atsuta M, Suzuki S. Adhesion of 4-META/MMA-TBB resin to collagen-depleted dentin -effect of conditioner with ascorbic acid/ferric chloride- Dent Mater J 2004; 23: 100-105.

13) Nomoto S, Kameyama A, Nakazawa T, Yazaki K, Amagai $T$, Kawada E, Oda Y, Hirai Y, Sato T. Influence of ascorbic acid on bonding of peroxide-affected dentin and 4-META/MMATBB resin. Clin Oral Investig 2006; 10: 325-330.

14) Mohammadi Z, Dummer PM. Properties and applications of calcium hydroxide in endodontics and dental traumatology. Int Endod J 2011; 44: 697-730.

15) Nandini S, Velmurugan N, Kandaswamy D. Removal efficiency of calcium hydroxide intracanal medicament with two calcium chelators: volumetric analysis using spiral CT, an in vitro study. J Endod 2006; 32: 1097-1101.

16) Rodig T, Vogel S, Zapf A, Hulsmann M. Efficacy of different irrigants in the removal of calcium hydroxide from root canals. Int Endod J 2010; 43: 519-527.

17) Balvedi RP, Versiani MA, Manna FF, Biffi JC. A comparison of two techniques for the removal of calcium hydroxide from root canals. Int Endod J 2010; 43: 763-768.

18) Lee BS, Lin YC, Chen SF, Chen SY, Chang CC. Influence of calcium hydroxide dressing and acid etching on the pushout bond strengths of three luting resins to root canal dentin. Clin Oral Investig 2014; 18: 489-498.

19) Windley W, 3rd, Ritter A, Trope M. The effect of short-term calcium hydroxide treatment on dentin bond strengths to composite resin. Dent Traumatol 2003; 19: 79-84.

20) Arslan H, Akcay M, Cakir M, Gok A, Yasa B, Dalli M. Comparison of bond strength of self-etch adhesive to pulp chamber dentin after placement of calcium hydroxide and various antibiotic pastes. Acta Odontol Scand 2015; 73: 226231.

21) Viotti RG, Kasaz A, Pena CE, Alexandre RS, Arrais CA, Reis AF. Microtensile bond strength of new self-adhesive luting agents and conventional multistep systems. J Prosthet Dent 2009; 102: 306-312.

22) Farina AP, Cecchin D, Barbizam JV, Carlini-Junior B. Influence of endodontic irrigants on bond strength of a selfetching adhesive. Aust Endod J 2011; 37: 26-30.

23) Fuentes MV, Ceballos L, Gonzalez-Lopez S. Bond strength of self-adhesive resin cements to different treated indirect composites. Clin Oral Investig 2013; 17: 717-724.

24) Suyama Y, de Munck J, Cardoso MV, Yamada T, Van Meerbeek B. Bond durability of self-adhesive composite cements to dentine. J Dent 2013; 41: 908-917.

25) Alves M, Campos F, Bergoli CD, Bottino MA, Ozcan M, Souza $R$. Effect of adhesive cementation strategies on the bonding of Y-TZP to human dentin. Oper Dent 2016; 41: 276-283.

26) Carvalho EM, De Souza WLP, Carvalho CN, Maciel AP, Loguercio AD, Bauer J. Effect of storage time on microtensile bond strength of self-adhesive and multi-step resin cements to dentin. Mat Res 2016; 19: 695-701.

27) Perdigao J, Gomes G, Lee IK. The effect of silane on the bond strengths of fiber posts. Dent Mater 2006; 22: 752-758.

28) Schmage P, Nergiz I, Markopoulou S, Pfeiffer P. Resistance against pull-out force of prefabricated coated FRC posts. J Adhes Dent 2011; 14: 175-182.

29) Xiong Y, Huang SH, Shinno Y, Furuya Y, Imazato S, Fok A, Hayashi M. The use of a fiber sleeve to improve fracture strength of pulpless teeth with flared root canals. Dent Mater 2015; 31: 1427-1434 